\title{
Relationship between transepidermal water loss and temperature of the measuring probe
}

\author{
S. Thoma ${ }^{1}$, J. Welzel ${ }^{1}$ and K.-P. Wilhelm ${ }^{2}$ \\ ${ }^{\prime}$ Department of Dermatology, Medical University of Lübeck and \\ ${ }^{2}$ proDERM Institute for Applied Dermatology Research, Schenefeld, Hamburg, Germany
}

\begin{abstract}
Background/aims: Transepidermal water loss (TEWL) is an important parameter for the determination of skin barrier function. The open chamber method has been established as the technique of choice in most dermatological laboratories for measurements of TEWL. However, the influence of the probe temperature on TEWL measurements has been the subject of recent controversial debates. In this study the relationship between TEWL measured with the Tewameter and temperature of the measuring probe was therefore investigated by comparing two different measuring techniques.

Methods: For one measurement, the probe was kept at room temperature $\left(20^{\circ} \mathrm{C}\right)$ and for the other one, the probe was preheated to the actual temperature of the measuring object before obtaining the values. Measurements were performed on evaporative standards (EvSs) and healthy individuals. For the EvSs, semipermeable membranes were pulled over a petri dish filled with water, which could be heated.
\end{abstract}

Results: TEWL values were found to depend on the temperature of the probe. TEWL values were higher when measured with the preheated probe. However, long-term measurements revealed that TEWL values measured with the unheated probe reached those higher TEWL values after approximately $8 \mathrm{~min}$ measuring time.

Conclusions: The final TEWL value was reached after shorter intervals for the preheated probe compared to the unheated probe $(2.5 \mathrm{~min}$ vs. $4 \mathrm{~min}$ ) for some measurements. However, preheating of the probe resulted in greater variability of the measurement values. Therefore, measurements with a preheated Tewameter probe is not be recommended.

Key words: transepidermal water loss - Tewameter - measuring probe - temperature.
$\mathrm{T}$ HE HUMAN skin provides a protective permeable barrier, mainly formed by the stratum corneum. This barrier can be evaluated by objective measurements of transepidermal water loss (TEWL).

For the measurement of TEWL, three methods exist: the closed chamber, the ventilated chamber, and the open chamber (1). The most established method is TEWL measurement with the open chamber method. Two different instruments are available so far. The Evaporimeter $^{(1)}$ (ServoMed, Stockholm, Sweden) and the Tewameter TM $210^{\circledR}$ (Courage \& Khazaka Electronic, Cologne, Germany), which was used for the measurements in this study.

Both instruments are based on the same measuring principle, which was described by Nilsson (1). But they also have differences, which have been pointed out recently by Barel and Clarys (2). Most importantly, measurements with the Tewameter yield significantly higher TEWL values than measurements with the Evaporimeter. It appears that differences in the con- struction of the measuring probe are the most likely explanation for the discrepancy between the two instruments (2).

To obtain a stable and reproducible TEWL value, many variables have to be kept constant, as it was defined by Pinnagoda et al. for the Evaporimeter ${ }^{\circledR}(3$, 4).

TEWL values are especially influenced by three different variables: the room temperature, the relative humidity (RH), and the temperature of the measured object, i.e., the skin. The sensors inside the open cylindrical chamber have to compensate for this difference in temperatures before a stable TEWL value can be calculated. This results in a fairly long measuring interval.

The relationship between the temperature of the measuring probe and TEWL values was investigated recently by Barel \& Clarys (2). They found increasing TEWL values with increasing probe temperature. 
In this study the relationship between TEWL and temperature of the probe was investigated more closely by comparing two different measuring methods. One method was the conventional procedure of leaving the probe at room temperature, and for the other measurement the probe was preheated.

The objective of this study was to find out whether heating the probe before measurements could shorten the measuring time needed in order to get a constant TEWL value. The stability and the change of TEWL values when measured with the preheated probe were also investigated. A further goal of this study was to elucidate whether or not the probe temperature and hence TEWL values were influenced by the heat of the investigator's hand.

\section{Material and Methods}

For the evaporative standard (EvSs), "constant water evaporation devices" (4) were used, which comprised petri dishes $(\varnothing 5 \mathrm{~cm})$ filled with distilled water $(10$ $\mathrm{ml}$ ) and covered with a semipermeable membrane. In this study, three different semipermeable membranes were used: Tegaderm ${ }^{\circledR}$ (3M Medica GmbH), OpSite ${ }^{\circledR}$ (TJ Smith and Nephew Limited), and Gore-Tex ${ }^{\circledR}$ (Material H; W.L. Gore \& Associates $\mathrm{GmbH}$ ). Polyethylene foil and Parafilm ${ }^{\circledR}$ (American National Can) with very little water vapour permeability were used as "negative standards". For each set 5 petri dishes were placed for $3 \mathrm{~h}$ at a defined membrane temperature (at $20^{\circ} \mathrm{C}$ and at $26^{\circ} \mathrm{C}-40^{\circ} \mathrm{C}$ in $2^{\circ} \mathrm{C}$-steps) on a hotplate in a transparent "open top" measuring box $(53.5 \mathrm{~cm} \times 33.5$ $\mathrm{cm} \times 50 \mathrm{~cm}$ ). The membrane temperature was measured with a digital thermometer. Each EvS was measured twice with the Tewameter for a period of $5 \mathrm{~min}$. One measurement was performed with the unheated measuring probe $\left(20^{\circ} \mathrm{C}\right)$ and the other one with the preheated probe. The probe was heated to the actual membrane temperature by placing it in a heatable probe-holder before starting the measurement (Fig. 1). The inside of the probe holder could be warmed to $40^{\circ} \mathrm{C}$ by a heatable foil fixed to the perimeter of the probe holder.

TEWL values were evaluated at two different times for each measurement. TEWL values were obtained when the measured values reached a defined standard deviation (SD) of $\leq 0.30 \mathrm{gh}^{-1} \mathrm{~m}^{-2}$ and $\leq 0.14$ $\mathrm{gh}^{-1} \mathrm{~m}^{-2}$, respectively. The SD was calculated for each measurement value by the Tewameter software, Tewaplot $1.4^{\circledast}$ (Courage \& Khazaka Electronic), which was used for measurement and documentation of the

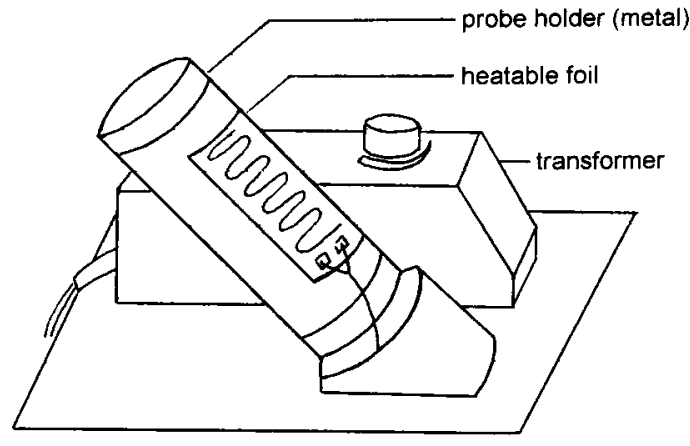

Fig. 1. Heatable probe holder $\left(20^{\circ} \mathrm{C}-40^{\circ} \mathrm{C}\right)$.

measuring curves. The averaging time chosen for the calculation of the mean TEWL value and the SD was $10 \mathrm{~s}$.

Long-term measurements were performed with EvSs (Gore-Tex and Tegaderm) at membrane temperatures of $38^{\circ} \mathrm{C}$ and $30^{\circ} \mathrm{C} / 32^{\circ} \mathrm{C}$. The measurements were continued with both the unheated and the preheated probe until the probe temperature was constant.

In vivo measurements were made at two skin areas (volar forearm and dorsum of the hand) of 20 healthy individuals after a $15 \mathrm{~min}$ rest period in a temperature and humidity controlled room. Each skin area was measured twice for $5 \mathrm{~min}$, once with the unheated probe and the other time with the preheated probe $\left(28^{\circ} \mathrm{C}\right)$ inside the measuring box. The skin temperature was measured before each measurement. For the evaluation of these measurements, TEWL values were corrected $\left(\mathrm{T}_{\text {corr }}\right.$ - TEWL) a standard reference temperature of $30^{\circ} \mathrm{C}$ by using the following equation (5):

$$
\mathrm{T}_{\text {corr }}-\mathrm{TEWL}=10^{(\log \mathrm{TEWL}+0.035(30-\mathrm{T}))}
$$

where $\mathrm{T}=$ measured skin temperature in ${ }^{\circ} \mathrm{C}$. Evaluation of TEWL values was done in the same manner as described for the measurements with the EvSs. The probe was held directly by hand during most measurements.

In order to find out if the probe was significantly heated by the investigator's hand, EvSs were measured with the unheated probe, which was held either by a probe holder clamp or by the uncovered hand of the investigator (skin temperature: $24.5^{\circ} \mathrm{C}$ ).

The measurements with the EvSs were performed during summer and autumn 1994, the long-term measurements as well as the in vivo measurements in the winter 1994/95. Room temperature for all measurements was $20^{\circ} \mathrm{C}-22^{\circ} \mathrm{C}$. Relative humidity was $50 \% \pm 5 \%$ (autumn, winter) and $60 \% \pm 8 \%$ (summer). 


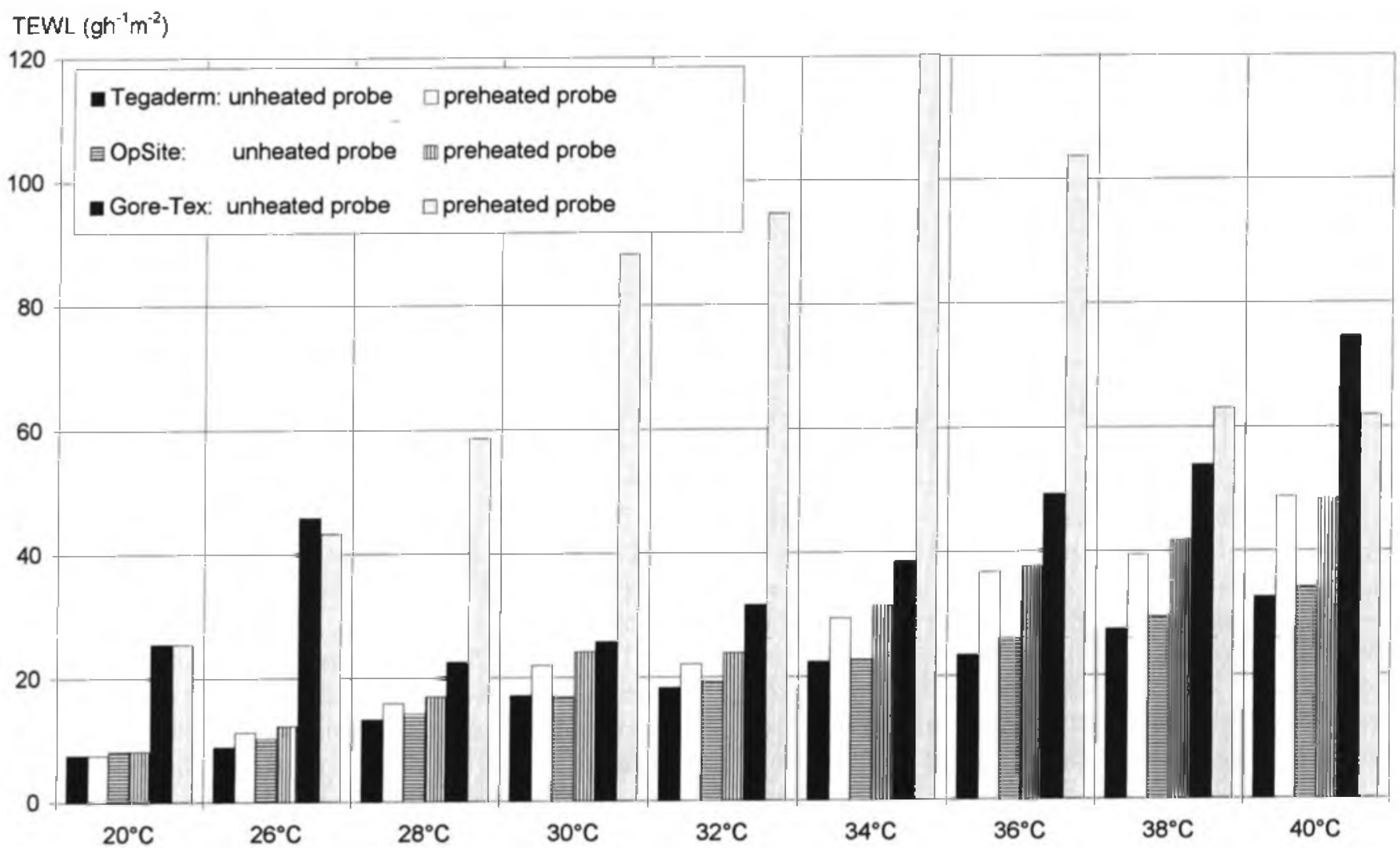

Fig. 2. Measurements with Tegaderm, Opsite and Gore-Tex; TEWL values are dependent on membrane temperature. Note, however, the decrease of TEWL values for Gore-Tex with the preheated probe and membrane temperature $\geq 38^{\circ} \mathrm{C}$ (mean values: $\mathrm{n}=5$ ).

\section{Results}

Measurements with evaporative standards For all membranes, the "TEWL" values increased with increasing membrane temperature. The slope of the increase in "TEWL" values depended on the water vapour permeability of the membrane. For most membranes, the "TEWL" values increased linearly (see Fig. 2). However, increasing the temperature did not influence the "TEWL" values of the occlusive foil Par- afilm, which was used as a negative control, because its water vapour permeability was very small.

The "TEWL" values of Gore-Tex displayed a different behaviour with respect to the membrane temperature. "TEWL" values increased as high as 120 $\mathrm{gh}^{-1} \mathrm{~m}^{-2}$ at a membrane temperature of $34^{\circ} \mathrm{C}$ when measured with the preheated probe. However, when membrane temperatures increased further, "TEWL" values declined and reached values of only about 60 $\mathrm{gh}^{-1} \mathrm{~m}^{-2}$ (membrane temperature $40^{\circ} \mathrm{C}$ ) (Fig. 2).

TABLE 1. Differences in TEWL values between measurements with preheated and unheated probe for different membrane temperatures

\begin{tabular}{|c|c|c|c|c|c|}
\hline \multirow{2}{*}{$\begin{array}{l}\text { Membrane } \\
\text { emperature in }{ }^{\circ} \mathrm{C}\end{array}$} & Tegaderm & OpSite & Polyethylene foil & Parafilm & Gore-Tex \\
\hline & \multicolumn{5}{|c|}{ Differences in TEWL values in $\mathrm{gh}^{-1} \mathrm{~m}^{-2}( \pm S . D)}$. \\
\hline 26 & $2.4( \pm 0.2)^{\star}$ & $2.0( \pm 0.1)^{*}$ & $-0.4( \pm 0.0)^{\star}$ & $-0.3( \pm 0.1)^{*}$ & $-2.5( \pm 0.1)$ \\
\hline 30 & $4.8( \pm 0.3)^{\star}$ & $7.2( \pm 0.4)^{*}$ & $0.2( \pm 0.1)$ & $-0.2( \pm 0.1)$ & $62.5( \pm 2.2)^{\star}$ \\
\hline 32 & $3.9( \pm 1.5)^{\star}$ & $4.6( \pm 0.3)^{\star}$ & $1.5( \pm 0.1)^{\star}$ & $0.0( \pm 0.1)$ & $63.1( \pm 7.1)^{\star}$ \\
\hline 34 & $7.0( \pm 1.1)^{*}$ & $8.7( \pm 0.6)^{*}$ & $1.8( \pm 0.8)^{*}$ & $-0.4( \pm 0.0)^{\star}$ & $81.9( \pm 10.0)^{*}$ \\
\hline 40 & $16.2( \pm 0.3)^{\star}$ & $14.2( \pm 1.3)^{*}$ & $2.7( \pm 0.7)^{*}$ & $1.4( \pm 0.1)^{*}$ & $-12.8( \pm 0.8)^{*}$ \\
\hline
\end{tabular}

$\mathrm{SD} \leq 0.14 \mathrm{gh}^{-1} \mathrm{~m}^{-2} ;\left(^{*}=P<0.05\right.$; Mann-Whitney-U-test (Wilcoxon-rank-sum-test); mean values: $n=5$. 
TABLE 2. Differences in measuring time until a stable TEWL value was obtained between measurements with unheated and preheated probe for different membrane temperatures

\begin{tabular}{|c|c|c|c|c|c|}
\hline $\begin{array}{l}\text { Membrane } \\
\text { emperature in }{ }^{\circ} \mathrm{C}\end{array}$ & Tegaderm & OpSite & Polyethylene foil & Parafilm & Gore-Tex \\
\hline 26 & $-1.2( \pm 15.3)$ & $26.0( \pm 52.5)$ & $-11.6( \pm 23.1)$ & $0.0( \pm 13.7)$ & $78.2( \pm 22.0)^{*}$ \\
\hline 30 & $92.4( \pm 9.2)^{\star}$ & $56.4( \pm 0.7)^{\star}$ & $58.0( \pm 30.7)$ & $68.0( \pm 6.2)$ & $56.4( \pm 16.1)$ \\
\hline 32 & $50.4( \pm 32.7)$ & $95.2( \pm 24.3)$ & $-23.2( \pm 22.0)$ & $-17.2( \pm 2.4)$ & $75.2( \pm 20.4)$ \\
\hline 34 & $99.0( \pm 9.5)^{*}$ & $129.6( \pm 22.7)$ & $50.4( \pm 10.3)$ & $-56.8( \pm 3.9)^{\star}$ & $92.6( \pm 42.9)$ \\
\hline 40 & $64.6( \pm 72.7)^{\star}$ & $54.8( \pm 23.4)$ & $-87.2( \pm 8.3)^{*}$ & $42.0( \pm 4.7)$ & $79.6( \pm 71.8)$ \\
\hline
\end{tabular}

$\mathrm{SD} \leq 0.14 \mathrm{gh}^{-1} \mathrm{~m}^{-2}$ indicates significant difference between unheated and preheated probe. $P<0.05 ;$ Mann-Whitney-U-test $(n=5)$.

"TEWL" values measured with the preheated probe were always higher than those values measured with the unheated probe (Table 1). The only exception was again Gore-Tex, but only at high
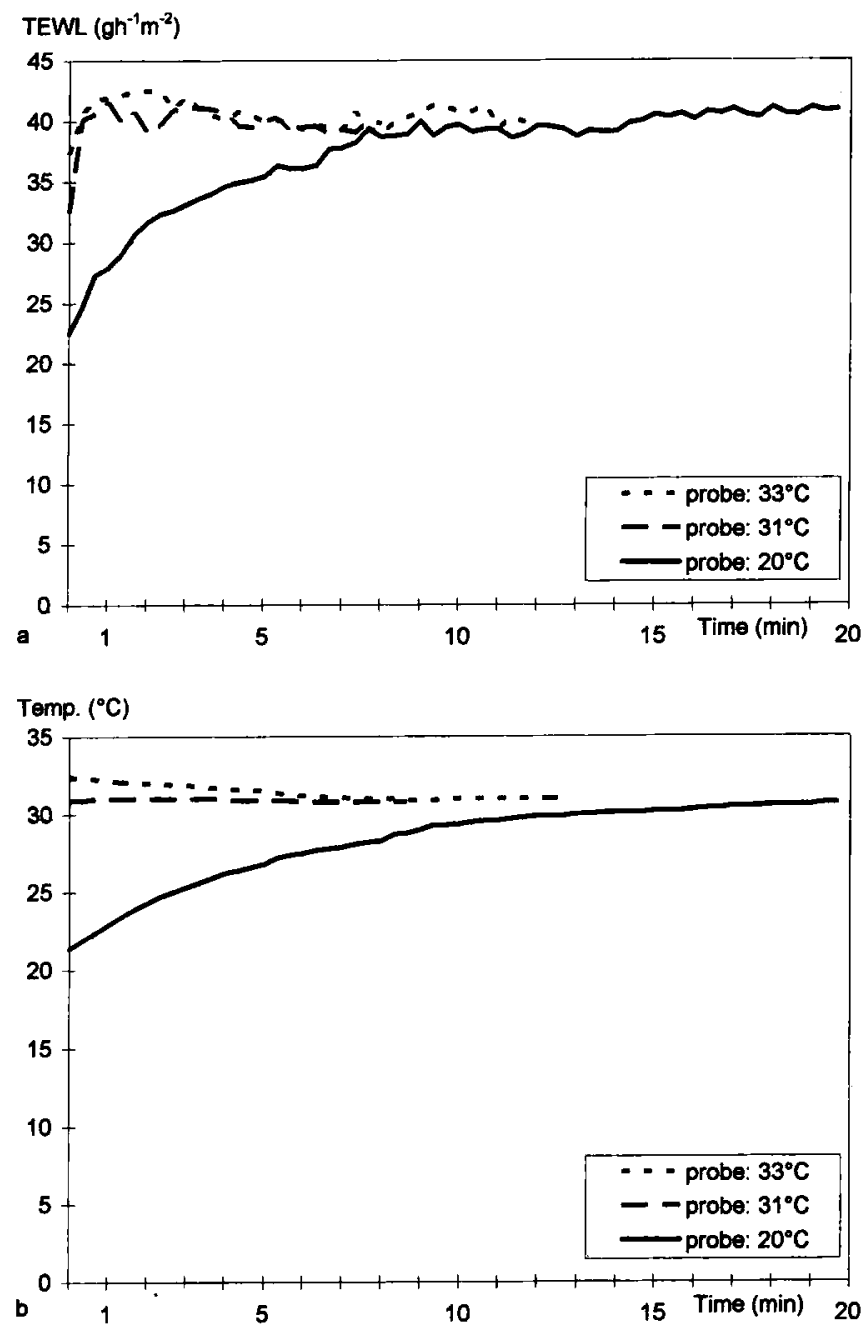

Fig. 3. Long-term measurements with Tegaderm (membrane temperature $38^{\circ} \mathrm{C}$ ). a) TEWL values as a function of measuring time; $b$ ) probe temperature as a function of measuring time. membrane temperatures. The negative control Parafilm also showed lower "TEWL" values when measured with the preheated probe for membrane temperatures up to $34^{\circ} \mathrm{C}$.

The final "TEWL" values for the membranes Tegaderm, OpSite, and Gore-Tex were reached after shorter intervals for the measurements with the preheated probe (Table 2). However, preheating the measuring probe did not shorten the measuring interval for the control membranes polyethylene foil and Parafilm.

\section{Long-term measurements}

TEWL values increased for up to $8 \mathrm{~min}$ when measured with the unheated probe $\left(20^{\circ} \mathrm{C}\right)$. By contrast the final value was reached after $1 \mathrm{~min}$ when measured with the preheated probe $\left(31^{\circ} \mathrm{C}\right)$. TEWL values measured were at the same level after 8 min measurement for both the unheated and preheated probe (Fig. 3a). However, the increase of the probe temperature, which rose in parallel to the increase in TEWL values, was going on slightly for up to $13 \mathrm{~min}$, when TEWL values were already constant (Fig. 3b).

For Gore-Tex (membrane temperature $38^{\circ} \mathrm{C}$ ), the measurement with the unheated probe showed an increase in TEWL values in the first $5 \mathrm{~min}$. However, when the probe was preheated to $38^{\circ} \mathrm{C}$, TEWL values as well as the probe temperature fell before becoming constant. After $6 \mathrm{~min}$, both probes were at a similar level (Fig. 4).

The final probe temperature did not equal the membrane temperature but remained always below it.

\section{In vivo measurements}

TEWL values measured at the volar forearm were $8.1( \pm 1.9) \mathrm{gh}^{-1} \mathrm{~m}^{-2}$ and for the dorsum of the hand were $16.7( \pm 4.5) \mathrm{gh}^{-1} \mathrm{~m}^{-2}$ (Fig. 5). TEWL values measured with the preheated probe were slightly 

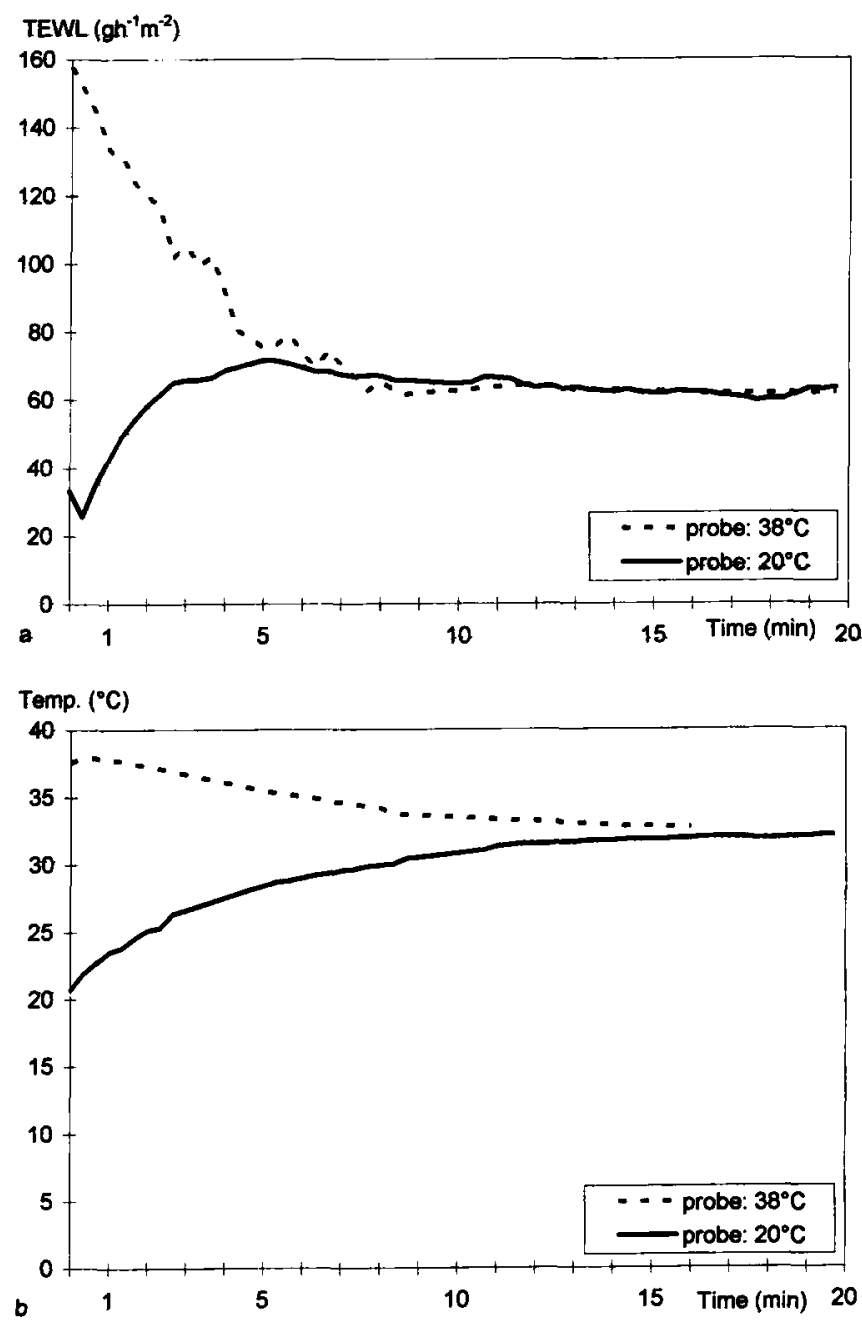

Fig. 4. Long-term measurements with Gore-Tex (membrane temperature $38^{\circ} \mathrm{C}$. a) TEWL values dependent on measuring time; b) probe temperature dependent on measuring time.

higher than TEWL values measured with the unheated probe (Fig. 5). Preheating of the probe tended to shorten the measuring interval until stable TEWL values were reached at the forearm, whereas it resulted in slightly longer measuring intervals at the dorsum of the hand.

\section{Comparative measurements between hand and} probe holder

There were no significant differences between TEWL value measurements carried out with the probe held either by the uncovered hand of the investigator or by a probe holder clamp (Table $3 a, b$ ). The probe temperature did not differ for both measurements.

\section{Discussion}

To investigate the relationship between TEWL and temperature of the measuring probe, two measuring

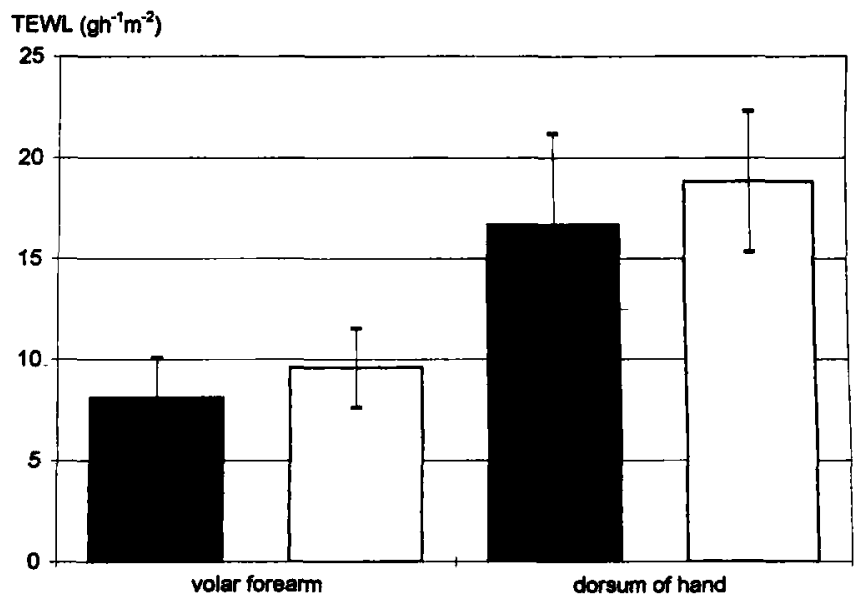

Fig. 5. In vivo measurements; $S D \leq 0.14 \mathrm{gh}^{-1} \mathrm{~m}^{-2}$ (mean values: $\mathbf{n}=$ 20); black hars: unheated probe; white bars: preheated probe.

methods were compared. EvSs were measured at different membrane temperatures by using an unheated probe $\left(20^{\circ} \mathrm{C}\right)$ and a preheated probe. TEWL values and TEWL value stability as well as the equilibration time were evaluated. The same was done with in vivo measurements.

\section{Measurements with evaporative standards}

The water vapour permeability of each membrane determined the magnitude of TEWL values. Therefore, TEWL values were close to zero for the occlusive membranes (polyethylene foil, Parafilm), but were extremely high for Gore-Tex. TEWL values increased with increasing membrane temperature.

We found a linear increase in TEWL values for the membranes. This is in contrast to previous studies on skin, where TEWL values increased exponentially with increasing skin temperature $(5,6)$.

The semipermeable membranes employed in our study do not possess a water holding capacity but have a far less complex structure than human skin. This could be the reason for the linear increase in TEWL values. Similarly, Grice reported a linear increase of

TABLE 3. Comparing measurements between hand-held probe and probe held by the probe holder clamp

\begin{tabular}{lll}
\hline TEWL values & $\begin{array}{l}\text { Tegaderm } \\
\text { TEWL }\left(\mathrm{gh}^{-1} \mathrm{~m}^{-2}\right)\end{array}$ & $\begin{array}{l}\text { Gore-Tex } \\
\text { TEWL }\left(\mathrm{gh}^{-1} \mathrm{~m}^{-2}\right)\end{array}$ \\
\hline $\begin{array}{lll}\text { Probe holder } \\
\text { Hand of the investigator }\end{array}$ & 10.9 & 29.8 \\
\hline Probe temperature & 10.9 & 30.7 \\
\hline Tegaderm & $\begin{array}{l}\text { Gore-Tex } \\
\text { temp. }\left({ }^{\circ} \mathrm{C}\right)\end{array}$ \\
\hline Probe holder & temp. $\left({ }^{\circ} \mathrm{C}\right)$ & 22.0 \\
Hand of the investigator & 22.5 & 21.9 \\
\hline
\end{tabular}


TEWL values with increasing skin temperature for damaged skin, i.e., psoriasis, because of the decreased water holding capacity of the damaged skin (7).

Although probably of little relevance for "real life" situations, our study points to a potential source of possibly erroneously low TEWL values for membranes with extremely high water vapour permeability when measured with high membrane temperature. Thus, TEWL values for Gore-Tex reached $120 \mathrm{gh}^{-1} \mathrm{~m}^{-2}$ for a membrane temperature of $34^{\circ} \mathrm{C}$. However, with further increasing membrane temperature TEWL did not increase further but decreased instead. A similar phenomenon was already described by Scott et al., who found that TEWL values measured with the Evaporimeter ${ }^{\circledR}$ did not increase over $75 \mathrm{gh}^{-1} \mathrm{~m}^{-2}$, although TEWL values measured with the ventilated chamber were higher under the same conditions (8).

In the instructions to the Tewameter by Courage \& Khazaka Electronic, it is mentioned that TEWL values over $70 \mathrm{gh}^{-1} \mathrm{~m}^{-2}$ would be measured too low, which is described as a "reduction-effect", explained by the arrangement of the open cylindrical chamber and the sensors, for which ideal conditions are assumed (9). If evaporation increases, the chamber restricts this higher evaporation and TEWL values cannot be calculated properly $(3,8,10)$. However, this phenomenon can only explain that the high TEWL values measured with the preheated probe were not correct because of an underestimation of any value exceeding 70 $\mathrm{gh}^{-1} \mathrm{~m}^{-2}$.

The paradoxical and unexpected decline of TEWL values for Gore-Tex temperatures higher than $34^{\circ} \mathrm{C}$ cannot be ascribed to this "reduction-effect" but may be caused by the algorithm employed for the calculation of TEWL. The formulas, which are used for the calculation of TEWL values, require two variables: temperature and $\mathrm{RH}$, both measured at the sensors inside the open chamber. The temperature influences the saturation vapour pressure psat (a). $\mathrm{RH}$ and $\mathrm{p}_{\text {sat }}$ determine the water vapour pressure $p(b)$. From the difference between the two water vapour pressures measured at both sensors, TEWL is calculated.

$\mathrm{p}_{\text {sat }}=6.112 \times \mathrm{e}^{15.634 \times[1-\mathrm{e}(\ln (273.16 / \mathrm{T}+273.16) \times 1.27)]}$

$\mathrm{P}=\mathrm{P}_{\text {sat }} \times \mathrm{RH}$ in $\% / 100$

where $\mathrm{T}=$ temperature at the sensor in $\mathrm{C}$.

For all measurements (Gore-Tex; preheated probe) with membrane temperatures from $36^{\circ} \mathrm{C}$ to $40^{\circ} \mathrm{C}$, the RH measured at the sensors was $100 \%$. This was investigated by using a special software (Tewaplot $1.4 \mathrm{rF}^{\circledR}$; Courage \& Khazaka Electronic) for the measurements, which displayed the values for the
$\mathrm{RH}$ at both pairs of sensors during the measurement. We found for these measurements a $\mathrm{RH}$ of $100 \%$ at both pairs of sensors. This means that the factor, which is multiplied by $p_{\text {sat }}$ equals $1(100 /$ $100=1$ ). Therefore, TEWL values were only determined by the difference of $p_{\text {sat }}$, which reflects only the temperature measured at the sensors. This could cause the decline of TEWL values for membranes with high evaporation.

\section{Long-term measurements}

Since TEWL values were nearly always higher for the measurements with the preheated probe for the EvSs as well as for the in vivo measurements, longterm measurements were performed. The consideration was that TEWL values measured with the unheated probe might have not reached their final values after $5 \mathrm{~min}$ measuring time. Therefore, measurements were performed until the probe temperature was constant.

Since TEWL values measured with the unheated probe were constantly increasing until they reached the same level of TEWL values measured with the preheated probe, TEWL values measured with the preheated probe could be considered "more accurate" values.

The other aspect investigated with the long-term measurements was the probe temperature. Barel and Clarys described the probe temperature reaching the skin temperature within 10 to $15 \mathrm{~min}$ (2). This could not be confirmed in our study. The probe temperature was indeed always lower than the membrane or skin temperature. For example, for a membrane temperature of $38^{\circ} \mathrm{C}$, the probe temperature did not increase above $31^{\circ} \mathrm{C}$ (Tegaderm). When the probe was preheated to the actual membrane temperature, it decreased the probe temperature.

\section{Equilibration time}

The final TEWL values were reached after shorter measuring intervals for membranes with high water vapour permeability (Tegaderm, OpSite, Gore-Tex). Since high TEWL values needed some time to reach a constant value, preheating the probe could shorten the measuring interval by skipping the warm-up period in the beginning of the measurement. However, the measuring interval needed for measurements with the preheated probe was not significantly shorter most times.

For the in vivo measurements, measuring intervals for measurements with the preheated probe were not significantly different from measuring intervals for measurements with the unheated probe. This oc- 
curred because preheating the probe resulted in greater variability of the measurements, so that TEWL values with a $S D \leq 0.14 \mathrm{gh}^{-1} \mathrm{~m}^{-2}$ still needed a long measuring interval.

This shows that the SD was not an ideal parameter for obtaining comparable TEWL values. For measurements with the unheated probe TEWL values increased slowly and without many fluctuations. Therefore a SD $\leq 0.14 \mathrm{gh}^{-1} \mathrm{~m}^{-2}$ was calculated over an averaging time of $10 \mathrm{~s}$ after a short measuring interval when TEWL values were still increasing and not constant.

For the measurement with the preheated probe, TEWL values increased rapidly. However, large variability of the measuring curve resulted for these measurements, so that the defined SD could not be calculated, although final TEWL values were essentially reached. Therefore, a defined measuring interval before obtaining TEWL values should be standardized, rather than using the SD of the measurement values.

The variability in TEWL values, which resulted when measurements were performed with the preheated probe, could be explained as follows: For measurements with the unheated probe the temperature of both sensors equaled the room temperature. By setting the probe on the skin or a warm membrane the warm air diffusing from this object heated the sensors slowly, reflected in a gradual increase of TEWL values.

For measurements with the preheated probe, where both sensors were preheated to the same temperature, only the lower sensors, receiving the warm air from the measuring area, maintained the temperature. However, the upper sensors were also in closer contact with the ambient air and were thus cooled. Simultaneously warm air from the skin also reached these sensors. From these turbulences inside the open chamber, fluctuations of TEWL values may have occurred.

\section{Comparative measurements between hand and probe holder}

The comparative measurements between the handheld probe and the probe held by the probe holder showed that it did not make any difference whether or not the probe was in contact with the uncovered hand of the investigator. Pinnagoda et al. described changes in TEWL values of $1-2 \mathrm{gh}^{-1} \mathrm{~m}^{-2}$ for measurements with the hand-held probe over a measuring time of $5 \mathrm{~min}$ with the Evaporimeter ${ }^{\circledR}(4)$. This was not found for measurements with the Tewameter.

\section{Conclusions}

Measurements with the preheated probe resulted in greater variability of TEWL values, which made it difficult to determine constant TEWL values. Therefore, constant TEWL values were not reached after a significantly shorter measuring interval for most measurements. Final TEWL values were only reached after a shorter measuring interval for membranes with high water vapour permeability and high membrane temperature. Therefore, we cannot recommend the measurement of TEWL with a preheated probe.

As our long-term measurements showed, a defined measuring time was more reliable for getting comparable TEWL values than the standard deviation of the measurement values as calculated by the Tewameter. Consequently, it should be recommended that TEWL values should be obtained after a standardized equilibration time.

In addition, wearing insulated gloves is not necessary when using the Tewameter.

\section{Acknowledgement}

We would like to thank Courage \& Khazaka Electronic, especially Mr Kläsgen and Mr Schöps, for programming the modified Tewaplot software and for indepth technical information about the Tewameter.

\section{References}

1. Nilsson GE. Measurement of water exchange through skin. Med Biol Eng Comput 1977: 15: 209-218.

2. Barel AO, Clarys P. Comparison of methods for measurement of transepidermal water loss. In Serup J, Jemec GBE, eds. Handbook of non-invasive methods and the skin. Boca Raton: CRC-Press, 1995: 179-184.

3. Pinnagoda J, Tupker RA. Measurement of the transepidermal water loss. In Serup J, Jemec GBE, eds. Handbook of non-invasive methods and the skin. Boca Raton: CRC-Press, 1995: 179-184.

4. Pinnagoda J, Tupker RA, Agner T, Serup J. Guidelines for transepidermal water loss (TEWL) measurement. A report from the Standardization Group of the European Society of Contact Dermatitis. Contact Derm 1990: 22: 164-178.

5. Mathias CGT, Wilson DM, Maibach HI. Transepidermal water loss as a function of skin surface temperature. J Invest Dermatol 1981: 77: 219-220.

6. Grice K, Satter H, Sharratt M, Baker H. Skin temperature and transepidermal water loss. J Invest Dermatol 1971: 57: 108-110.

7. Grice K. Transepidermal water loss in pathological skin. In: Jarrett A, ed. The physiology and pathophysiology of the skin, Vol. 6. London: Academic Press, 1980: 2147-2155.

8. Scott RC, Oliver GJA, Dugard PH, Singh HJ. A comparison of techniques for the measurement of transepidermal water loss. Arch Dermatol Res 1982: 274: 57-64. 
9. Information and instructions to Tewameter TM 210. Cologne: Courage \& Khazaka Electronic GmbH, 1993.

10. Wheldon AE, Monteith JL. Performance of a skin evaporimeter. Med Biol Eng Comput 1980: 18: 201-205.
Address:

Klaus-Peter Wilhelm

proDERM

Institute for Applied Dermatological Research

Industriestr. 1

D-22869 Schenefled/Hamburg

Germany

Tel: $+40-8393580$

Fax: $+40-8406659$ 